\title{
Vitamin D Supplementation for Nonspecific Musculoskeletal Pain in Non-Western Immi- grants: A Randomized Controlled Trial
}

Ferdinand Schreuder, $M D^{1}$

Roos M. D. Bernsen, $P b D^{2}$

Jobannes C. van der Wouden, $P b D^{1}$

'Department of General Practice, Erasmus

MC, Rotterdam, The Netherlands

${ }^{2}$ Department of Community Medicine, United Arab Emirates University, United Arab Emirates
AC Annals Journal Club selection; see inside back cover or http://www. annfammed.org/AJC/.

Conflicts of interest: authors report none.

\section{CORRESPONDING AUTHOR}

Ferdinand Schreuder, MD

Handellaan 108-D

2625 SN Delft

The Netherlands

fschreuder01@planet.nl

\begin{abstract}
PURPOSE Many non-Western immigrants report musculoskeletal pains that are hard to treat. We studied the effect of high-dose vitamin $D_{3}$ on nonspecific persistent musculoskeletal complaints in vitamin D-deficient non-Western immigrants and assessed correlation of pain patterns with benefit.
\end{abstract}

METHODS We conducted a semi-crossover randomized controlled trial between February 2008 and February 2010 in primary care in 84 non-Western immigrants visiting their general practitioner for nonspecific musculoskeletal pain. At baseline, patients were randomized to placebo or vitamin D $(150,000 \mathrm{IU}$ vitamin $D_{3}$ orally); at week 6 , patients in the original vitamin $D$ group were randomized a second time to receive vitamin D (again) or to switch to placebo, whereas patients in the original placebo group were all switched to vitamin D. The main outcome was self-assessed change in pain after the first 6 weeks.

RESULTS Patients in the vitamin D group were significantly more likely than their counterparts in the placebo group to report pain relief 6 weeks after treatment $(34.9 \%$ vs $19.5 \%, P=.04)$. The former were also more likely to report an improved ability to walk stairs $(21.0 \%$ vs $8.4 \%, P=.008)$. Pain pattern was not correlated with the success of treatment. In a nonsignificant trend, patients receiving vitamin D over 12 weeks were more likely to have an improvement than patients receiving it over 6 weeks.

CONCLUSIONS There is a small positive effect 6 weeks after high-dose vitamin $D_{3}$ on persistent nonspecific musculoskeletal pain. Future research should focus on longer follow-up, higher supplementation doses, and mental health.

Ann Fam Med 2012;10:547-555. doi:10.1370/afm.1402.

\section{INTRODUCTION}

$\mathrm{M}$ any studies report a beneficial effect of vitamin D supplementation on musculoskeletal diseases or complaints; they include not only well-described case reports, ${ }^{1-3}$ but also large intervention studies. ${ }^{4}$ Their findings seem to be in line with several cross-sectional studies that have identified a relationship between low serum vitamin D levels and musculoskeletal complaints ${ }^{5-7}$ and muscle weakness. ${ }^{8-11}$ It is not clear whether the pain associated with low vitamin $\mathrm{D}$ levels is mainly proximal (as in the case of osteomalacia), ${ }_{1}^{12}$ is confined to the low back ${ }^{4}$ or legs ${ }_{1}^{13}$ or is widespread. ${ }^{14,15}$ Other studies have not found any association with pain. ${ }^{15,16}$

The discovery of vitamin D receptors in muscle cells ${ }^{17-19}$ prompted investigators to look for a muscle analog of osteomalacia. Because vitamin D supplementation may enhance muscle strength, ${ }^{9,20,21}$ supplementation could also be an easy and inexpensive way to manage nonspecific musculoskeletal pain. This intervention would be of special interest for non-Western immigrants in western Europe, who are prone to vitamin D deficiency and also more often have musculoskeletal problems than white people. ${ }^{22-27}$ 
Several nonblinded studies and case reports have documented relief of nonspecific musculoskeletal pain after supplementation with various doses and forms of vitamin D. Gloth et $\mathrm{al}^{1}$ reported reduced pain 1 week after administration of 50,000 IU vitamin $\mathrm{D}_{2}$ in 3 elderly patients. Investigators in the Netherlands have described resolution of long-standing pain 6 weeks after administration of 1,200 IU vitamin $\mathrm{D}_{2}$ daily in 3 Turkish women ${ }^{27}$ as well as in 3 girls after several weeks to months of treatment with 2,000 to 3,000 IU vitamin D daily. ${ }^{28}$ Eleven severely deficient asylum-seeking women had relief of long-standing pain 4 to 13 weeks after a single dose of 300,000 IU vitamin D given intramuscularly. ${ }^{13}$ Seventy vitamin D-deficient women in the Arab United Emirates recovered 4 weeks after injection of 600,000 IU vitamin $\mathrm{D}_{3}$ or 8 weeks after the start of oral supplementation with $50,000 \mathrm{IU} / \mathrm{wk}^{29}$

In a recent Cochrane systematic review, however, Straube et $\mathrm{al}^{30}$ did not find evidence for a positive effect of vitamin D therapy and concluded that randomized controlled trials (RCT) are needed to shed light on this issue. After this review, 2 RCTs were published. One trial did not find a pain-relieving effect of vitamin $\mathrm{D}_{3}$ (800 IU/d or 2 treatments with $10,000 \mathrm{IU})$ at 6 months in vitamin D-deficient non-Western immigrants aged 18 to 65 years, the majority of whom had fibromyalgia ${ }^{31}$; however, this trial was not designed to evaluate the pain-modifying effect of vitamin $\mathrm{D}$. The other trial was done in elderly Turkish patients from a rheumatology clinic (patients with fibromyalgia were excluded) and found no differences in pain as assessed with a visual analogue scale 4 weeks after administration of 300,000 IU vitamin D (orally or intramuscularly) vs placebo. ${ }^{32}$

We aimed to assess the effect of high-dose vitamin D supplementation on nonspecific musculoskeletal symptoms in non-Western vitamin D-deficient immigrants.

\section{METHODS}

\section{Study Area, Population, and Design}

This semi-crossover randomized controlled trial was conducted between February 2008 and February 2010 in 10 general practices in Delft, The Netherlands, among non-Western immigrants and their offspring, mainly born in the Middle East, Turkey, northern Africa, and Somalia, aged 18 to 60 years, who visited their doctor for frequent, recurrent musculoskeletal pain or pain lasting more than 3 months without an obvious cause (eg, trauma, arthritis, or sciatica). They were tested for vitamin $\mathrm{D}$ deficiency, which we defined arbitrarily as a level of 25-hydroxyvitamin D (25-OHD) of less than $50 \mathrm{nmol} / \mathrm{L}$. Patients who were deficient and met inclusion and exclusion criteria (Table 1) were invited to participate in the study by interpreters who were trained at introducing the study and explaining the questionnaires. Medical care was continued as usual and could include advice and prescription of physiotherapy or medication, but not supplementation with vitamin D. The study was approved by the Medical Ethical Board South West Holland and registered in the international trial register (ISRCTN54027991).

At baseline, 2 independent pharmacists unaware of patients' treatment allocation dispensed either oral vitamin D $\left(150,000\right.$ IU vitamin $\mathrm{D}_{3}$ in $7.5 \mathrm{~mL}$ oil ${ }_{i}$ Vigantol, Merck) or oral placebo (7.5 mL oil having same appearance and taste). Bottles were numbered according to a computer-generated randomization list. At week 6, a second randomization was done for patients who had received vitamin $\mathrm{D}$ at baseline, but all patients who had received placebo at baseline now received vitamin $\mathrm{D}$. Patients, general practitioners, and interviewers were blinded during the whole trial period. This randomization procedure resulted in 3 groups: one given vitamin $\mathrm{D}$ at both baseline and 6 weeks, a second given vitamin $\mathrm{D}$ at baseline followed by placebo at 6 weeks, and a third given placebo at baseline and vitamin D at 6 weeks. We chose this design to ensure that all patients received at least some supplementation; to be able to compare at 12 weeks a repeated dose with a single dose $e_{i}$ to assess a possible delayed effect of vitamin D supplementation by comparing the vitamin D-placebo group and the placebo-vitamin D group; and to permit comparisons for individual patients of the response to a single dose at 6 weeks with a single dose at 12 weeks.

The interpreters conducted interviews at baseline and at week 6 and week 12. At all time points, patients rated their pain levels in 4 areas of the body on questionnaires using a visual analogue scale (VAS, range, 0-100) and localized pain by marking a mannequin. Use of painrelieving drugs and physiotherapy were also assessed.

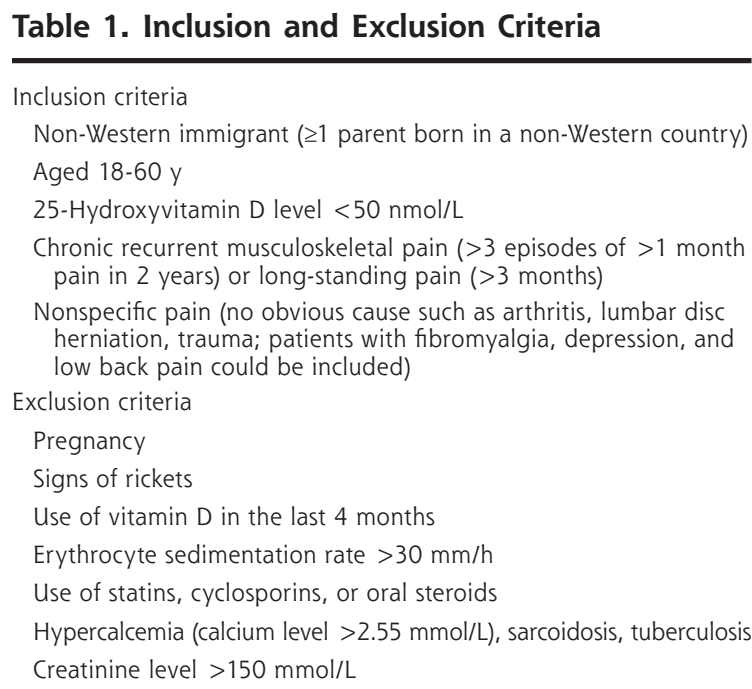


At both week 6 and week 12, patients were asked about improvement or deterioration (compared with baseline) of their pain on a 5 -point Likert scale and about adverse effects. We also assessed self-reported improvement in ability to walk stairs at week 6 and week 12 .

At baseline and at week 12, we measured levels of 25-OH-D in serum by radioimmunoassay (Diasorin by SSDZ, Delft). The interassay coefficient of variation was less than $13 \%$. At the end of the study, general practitioners were asked to report any adverse effects and any specific diagnoses (eg, arthritis, sciatica, trauma) made. Patients in whom a specific diagnosis had been made were excluded from analyses.

The trial's primary outcome was self-reported change in pain after the first 6 weeks of treatment on a 5 -point Likert scale. Prespecified secondary outcomes were change in pain at week 12 (Likert scale), selfreported change in ability to walk stairs at week 6 and week 12 (also Likert scales), and VAS scores measuring pain in the neck/shoulders, low back, arms, and legs/ joints, and measuring ability to walk stairs.

\section{Sample Size Calculation}

In calculations, we assumed a significance level of $5 \%$, a power of $80 \%$, and an improvement in $10 \%$ of the patients who received placebo at baseline and in $40 \%$ of the patients who received vitamin $\mathrm{D}$ at baseline. A sample size of 76 patients (38 in each group) would be sufficient to detect this difference. This estimate is conservative because it is based on a dichotomous outcome (improved vs not improved), whereas the actual outcome variable is an ordinal variable with 5 levels.

\section{Definitions}

We defined treatment success as any improvement in reported pain (either "much less pain" or "less pain") after the first 6 weeks of treatment. Joint pain was pain in joints only, including pain in the upper arm at the side of a painful shoulder. Proximal pain was pain in the proximal legs and arms, both left and right (lower axial pain could replace pain in proximal legs, and upper axial pain was considered equivalent to pain in the proximal arms). Widespread pain was axial pain plus pain on both sides of the body affecting at least 1 arm or leg. ${ }^{33}$ These 3 subgroups based on pain pattern may overlap.

\section{Statistical Analysis}

For our primary outcome, we tested the difference at 6 weeks between the 2 groups of patients who received placebo or vitamin $\mathrm{D}$ at baseline with the Pearson $\chi^{2}$ test for trends. To adhere as much as possible to the intention-to-treat principle, we imputed only the primary variable (Likert scale), by assessing the association between VAS and Likert scale for patients who had both variables available. We used this association to impute the Likert scale for those with missing Likert scale data. This strategy (use of the association between the incomplete variable with $\geq 1$ complete variables) is a common approach for imputing missing values and was used for the Likert scale pain (4 patients) and the Likert scale ability to walk stairs (5 patients).

For self-reported change in ability to climb stairs at 6 weeks, the analysis was similar to the one used for the primary outcome.

To explore whether any difference in effect of vitamin D and placebo might be explained by other interventions, we tested the difference in use of physiotherapy and medication between the 2 groups at 6 weeks (with the Pearson $\chi^{2}$ test and Mann-Whitney U test, respectively).

We evaluated 3 VAS outcomes: (1) average VAS (of pain scores for pain in neck and shoulders, low back, arms and legs, and joints), (2) maximum VAS (of these 4 pain scores), and (3) VAS disability in climbing stairs. The absolute difference in improvement between baseline and week 6 for these outcomes between the 2 groups given placebo and vitamin $\mathrm{D}$ at baseline was tested with linear regression analysis using the respective baseline VAS score as a covariate.

\section{Determinants of Treatment Success}

To explore determinants of treatment success, we calculated percentages of patients having success in subgroups based on age, sex, season of enrollment, baseline pain characteristics, baseline VAS scores, and baseline vitamin D levels. Univariate associations of success with these determinants were tested with Pearson $\chi^{2}$ tests with a continuity correction for nominal determinants and with the Student $t$ test for continuous determinants. Determinants (mentioned above) with $P$ values less than .10 were tested in a stepwise (backward Wald) multivariate logistic regression model with success as the dependent variable.

To compare the effects of a single dose vs repeated doses of vitamin $\mathrm{D}$, we tested the difference between the vitamin D-placebo group and the vitamin D-vitamin D group in terms of the self-reported change in pain at 12 weeks and the change in ability to climb stairs (on 5 -point Likert scales) with the Pearson $\chi^{2}$ test for trend.

\section{Possible Delayed Effect of Vitamin D Supplementation}

To explore a possible delayed effect of vitamin D supplementation, we compared pain improvement at 12 weeks among the 3 groups by means of the Kruskall-Wallis test. When the result was significant, we conducted a pairwise comparison with a Pearson $\chi^{2}$ test for trend using a Bonferroni correction. 
RESULTS

A total of 88 patients were screened for eligibility, of whom 84 (95\%) were enrolled (Figure 1). Fifteen patients did not complete the full protocol because they did not attend the second interview (5 patients) or third interview (10 patients). Analysis of outcomes at 6 weeks were based on 79 patients.

Baseline demographic and laboratory characteristics were balanced between the groups, as was season of enrollment (Table 2). Overall, $77.4 \%$ of patients

\section{Figure 1. Patient enrollment, randomization, and disposition.}

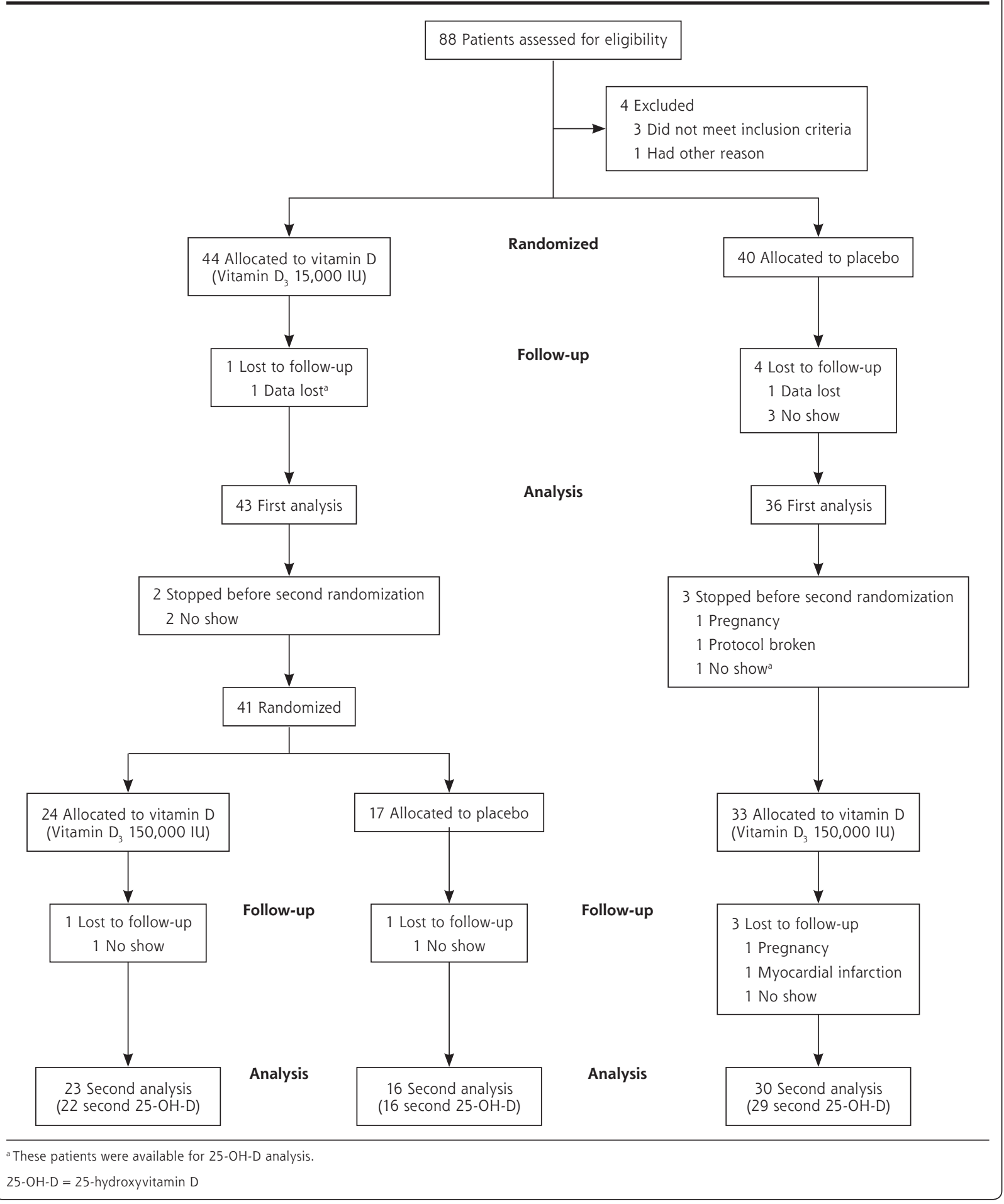


Table 2. Patient Characteristics at Baseline, Overall and by Subsequent Group

\begin{tabular}{|c|c|c|c|c|c|c|}
\hline \multirow[b]{2}{*}{ Characteristic } & \multirow[b]{2}{*}{$\begin{array}{c}\text { Total } \\
(\mathrm{N}=84)\end{array}$} & \multicolumn{2}{|c|}{ Week 6 Group } & \multicolumn{3}{|c|}{ Week 12 Group } \\
\hline & & $\begin{array}{l}\text { Vitamin } D \\
(n=44)\end{array}$ & $\begin{array}{l}\text { Placebo } \\
(\mathrm{n}=40)\end{array}$ & $\begin{array}{c}\text { Vitamin D- } \\
\text { Vitamin D } \\
(n=24)\end{array}$ & $\begin{array}{c}\text { Vitamin D- } \\
\text { Placebo } \\
(n=17)\end{array}$ & $\begin{array}{c}\text { Placebo- } \\
\text { Vitamin D } \\
(\mathrm{n}=33)\end{array}$ \\
\hline Age, mean (SD), y & $41.9(10.4)$ & $42.9(9.5)$ & $40.8(11.3)$ & $42.9(10.0)$ & $43.8(9.4)$ & $41.2(11.5)$ \\
\hline Sex, female, No. (\%) & $64(76.2)$ & $37(84.1)$ & $28(70.0)$ & $21(87.5)$ & $13(76.5)$ & $22(66.7)$ \\
\hline Enrolled October-March, No. (\%) & $47(54.8)$ & $28(63.6)$ & $19(47.5)$ & $13(54.2)$ & $13(76.5)$ & $14(42.4)$ \\
\hline 25-OH-D, mean (SD), nmol/L & $19.7(9.7)$ & $19.7(10.7)$ & $19.7(8.8)$ & $20.2(10.3)$ & $18.9(12.5)$ & $19.6(9.0)$ \\
\hline Physiotherapy in past month, No. (\%) & $15(17.9)$ & $8(18.2)$ & $7(17.5)$ & $2(8.3)$ & $5(29.4)$ & $7(21.2)$ \\
\hline $\begin{array}{l}\text { Number of days of pain medication in past } \\
\text { week, mean (SD) }\end{array}$ & $2.8(2.8)$ & $2.5(2.9)$ & $3.2(2.8)$ & $1.5(2.3)$ & $3.7(3.2)$ & $3.2(2.8)$ \\
\hline \multicolumn{7}{|l|}{ Pain characteristics ${ }^{\mathrm{a}}$} \\
\hline Widespread pain, No. (\%) & $44(52.4)$ & $22(50.0)$ & $22(55.0)$ & $8(33.3)$ & $12(70.6)$ & $19(57.6)$ \\
\hline Proximal pain, No. (\%) & $5(6.0)$ & $3(7.0)$ & $2(5.0)$ & $3(12.5)$ & $0(0.0)$ & $1(3.0)$ \\
\hline Joint pain, No. (\%) & $9(10.7)$ & $6(14.0)$ & $3(7.5)$ & $5(20.8)$ & $1(5.9)$ & $1(3.0)$ \\
\hline \multicolumn{7}{|l|}{ VAS pain scores ${ }^{b}$} \\
\hline Highest, ${ }^{c}$ mean (SD) & $86.1(16.9)$ & $83.0(20.6)$ & $89.5(11.0)$ & $79.0(24.9)$ & $86.4(13.1)$ & $90.7(9.9)$ \\
\hline Average, ${ }^{\mathrm{d}}$ mean $(\mathrm{SD})$ & $62.7(19.4)$ & $60.6(21.2)$ & $65.1(17.2)$ & $56.4(24.4)$ & $65.2(16.1)$ & $66.0(17.1)$ \\
\hline VAS difficulty climbing stairs, mean (SD) ${ }^{\mathrm{e}}$ & $64.6(29.4)$ & $62.5(31.6)$ & $66.9(26.9)$ & $60.1(30.2)$ & $66.6(35.0)$ & $71.2(24.6)$ \\
\hline \multicolumn{7}{|c|}{$25-\mathrm{OH}-\mathrm{D}=25$-hydroxyvitamin $\mathrm{D} ; \mathrm{VAS}=$ visual analogue scale. } \\
\hline \multicolumn{7}{|c|}{$\begin{array}{l}\text { a See Methods for definitions. } \\
\text { b Possible scores ranged from } 0 \text { to } 100 \text {, with higher scores indicating worse pain. } \\
\text { 'Mean of the highest VAS pain scores per patient at baseline. } \\
\text { dAverage VAS pain score for arms, legs, low back, and neck/shoulders per patient at baseline. } \\
\text { e Possible scores ranged from } 0 \text { to } 100 \text {, with higher scores indicating greater difficulty. }\end{array}$} \\
\hline
\end{tabular}

were female, and $53.0 \%$ had widespread pain, with high VAS scores (mean, 86.1) The mean 25-OH-D level at baseline was $19.7 \mathrm{nmol} / \mathrm{L}$. Initial VAS scores and use of concomitant treatment were lower in the vitamin Dvitamin D group as compared with the other groups; the groups did not differ with respect to other clinical features.

\section{Primary Outcome: Change in Pain at 6 Weeks}

Primary efficacy analyses showed the vitamin D group was significantly more likely to report their pain was improved at week 6 when compared with the placebo group (34.9\% vs $19.5 \%, P=.04$ ) (Table 3 ). Also noteworthy was a lower rate of worsening of pain in the former group (25.6\% vs $44.4 \%$ ). The 2 groups were similar with respect to use of physiotherapy or painrelieving medication (data not shown).

\section{Secondary Outcomes}

Patients in the vitamin D were also markedly more likely than those in the placebo group to have an improvement in self-reported ability to walk stairs at 6 weeks $(21.0 \%$ vs $8.4 \%, P=.008)$ (Table 4$)$. Here, too, the vitamin D group was much less likely to have deterioration than the placebo group (23.3\% vs $55.5 \%$ ).

Improvements in VAS scores for pain and for ability to walk stairs with vitamin D did not reach statistical significance.

\section{Determinants of Treatment Success}

In the entire study population, localization of pain or clinical patterns such as proximal pain or widespread pain were not correlated with improvement at 6 weeks in univariate analysis, except for pain in the legs and disability in climbing stairs (Table 5). In a multivariate analysis, pain in the legs remained the only significant variable in the model: patients having a higher 
VAS score for pain in the legs at baseline had significantly lower odds of an improvement in pain (odds ratio $=0.20 ; 95 \%$ confidence interval, 0.06-0.68). We found no association between 25-OH-D levels at baseline and improvement at week 6 .

\section{Possible Delayed Effect of Supplementation}

Changes in pain differed significantly among the 3 groups $(P=.006)$. Pairwise comparisons revealed that only the difference between vitamin D-vitamin D group and the placebo-vitamin D group was significant $(P=.005)$, with a larger proportion of patients in the former group having an improvement of pain
(Table 6). Differences between week 6 and week 12 were not significant.

\section{Adverse Effects}

We did not find any adverse effects of vitamin D supplementation during or after the trial.

\section{DISCUSSION}

We found an improvement in self-assessed pain 6 weeks after administration of 150,000 IU vitamin $D_{3}$ in non-Western immigrants having vitamin $\mathrm{D}$ deficiency. Improvement was also seen in the ability to walk stairs, and there was a weak trend toward greater benefit after 12 weeks vs 6 weeks of supplementation. Having less vs more pain in the legs was associated with better odds of improvement in both pain and stair-walking ability. In contrast to the findings for self-assessed change in pain on Likert scales, VAS scores for pain did not improve significantly after supplementation with vitamin D.

Our results are in line with several case reports but not with the results of 2 trials conducted in the United States. These trials included mainly white patients having long-standing pain with a

Table 5. Determinants of Treatment Success in the Total Study Population

\begin{tabular}{|c|c|c|c|c|c|}
\hline Determinant & $\begin{array}{c}\text { Treatment } \\
\text { Success, n/N (\%) }\end{array}$ & $P$ Value & Determinant & $\begin{array}{c}\text { Treatment } \\
\text { Success, n/N (\%) }\end{array}$ & $P$ Value \\
\hline Age, y & & .74 & VAS pain arms & & .19 \\
\hline$<45$ & $9 / 40(22.5)$ & & $\leq$ Median & $13 / 39(33.3)$ & \\
\hline$\geq 45$ & 10/35 (28.6) & & $>$ Median & $6 / 35(17.1)$ & \\
\hline Sex & & .20 & VAS pain neck/shoulders & & .14 \\
\hline Female & $17 / 57(29.8)$ & & $\leq$ Median & $13 / 38(34.2)$ & \\
\hline Male & $2 / 18(11.1)$ & & > Median & $6 / 36(16.7)$ & \\
\hline Enrolled & & .32 & VAS pain legs & & .01 \\
\hline October-March & $13 / 42(31.0)$ & & $\leq$ Median & $15 / 38(39.5)$ & \\
\hline April-September & 6/33 (18.2) & & $>$ Median & 4/35 (11.4) & \\
\hline Joint pain & & .34 & VAS pain back & & .29 \\
\hline No & $16 / 69(23.2)$ & & $\leq$ Median & $12 / 37(32.4)$ & \\
\hline Yes & $3 / 6(50.0)$ & & $>$ Median & $7 / 37(18.9)$ & \\
\hline Proximal pain & & .80 & VAS disability climbing stairs & & .01 \\
\hline No & $17 / 70(24.3)$ & & $\leq$ Median & $14 / 36(38.9)$ & \\
\hline Yes & $2 / 5(40.0)$ & & > Median & $4 / 36(11.1)$ & \\
\hline Widespread pain & & .94 & Baseline 25-OH-D & & 1.00 \\
\hline No & $9 / 33(27.3)$ & & $<25 \mathrm{nmol} / \mathrm{L}$ & $13 / 54(24.1)$ & \\
\hline Yes & $10 / 42(23.8)$ & & $\geq 25 \mathrm{nmol} / \mathrm{L}$ & $4 / 16(25.0)$ & \\
\hline
\end{tabular}

VAS = visual analogue scale; $25-\mathrm{OH}-\mathrm{D}=25$-hydroxyvitamin $\mathrm{D}$.

Notes: Treatment success was defined as any improvement in pain 6 weeks after treatment. Stepwise logistic regression analysis with the 2 significant determinants in univariate analysis showed that the VAS score for pain in the legs was the only significant $(P=.01$ ) predictor of success (odds ratio $=0.20 ; 95 \%$ confidence interval, 0.06-0.68), whereby patients having a higher VAS score for pain in the legs at baseline had less improvement in pain 6 weeks after vitamin D supplementation. 
Table 6. Change in Self-Assessed Pain at 12 Weeks by Group

\begin{tabular}{|c|c|c|c|c|c|}
\hline Group & $\begin{array}{c}\text { Much Less Pain } \\
\text { No. }(\%)\end{array}$ & $\begin{array}{l}\text { Less Pain } \\
\text { No. }(\%)\end{array}$ & $\begin{array}{c}\text { Equal } \\
\text { No. (\%) }\end{array}$ & $\begin{array}{l}\text { More Pain } \\
\text { No. }(\%)\end{array}$ & $\begin{array}{c}\text { Much More Pain } \\
\text { No. }(\%)\end{array}$ \\
\hline Vitamin D-vitamin D & $4(19.0)$ & $9(42.9)$ & $5(23.8)$ & $1(4.8)$ & $2(9.2)$ \\
\hline Placebo-vitamin D & $2(6.3)$ & $2(6.3)$ & $16(50.0)$ & $6(18.8)$ & $6(18.8)$ \\
\hline Vitamin D-placebo & $1(5.9)$ & $6(35.3)$ & $5(29.4)$ & $5(29.4)$ & $0(0)$ \\
\hline
\end{tabular}

mean 25-OH-D level of $45 \mathrm{nmol} / \mathrm{L}$. The first trial compared 13 treatments of 50,000 IU vitamin $\mathrm{D}_{2}$ in 3 months vs placebo in 42 patients and found no differences in VAS pain scores. ${ }^{34}$ One-half of the placebo group had normalization of their 25-OH-D levels by exposure to sunshine. The second trial found no improvement in several pain scores after 8 weeks of 50,000 IU vitamin $D_{3}$ weekly. ${ }^{35}$ The authors mention the short duration of the trial as a possible reason for this negative result. Nevertheless, there was a significant improvement in ability to walk stairs in their treatment group.

What could explain the differences between these findings and ours? First, in our trial, designed for optimal applicability in clinical practice, we chose to assess self-assessed change in pain as a measure close to physicians' typical way of evaluating pain treatment. This verbal score is used before and is probably more reliable than the VAS scores. ${ }^{29,36-38}$ Second, the difference in population (white vs non-Western) and $25-\mathrm{OH}-\mathrm{D}$ levels at baseline $(45 \mathrm{nmol} / \mathrm{L}$ vs $20 \mathrm{nmol} / \mathrm{L})$ between our study and the study of Warner et al, ${ }^{34}$ and the spontaneous improvement of 25-OH-D levels in that small study, might explain the lack of an effect. ${ }^{39}$ Third, the vitamin $\mathrm{D}_{2}$ used in that study might have had less effect than the vitamin $D_{3}$ we used. ${ }^{40-43}$

Another RCT assessing the effect of vitamin D supplementation on pain was published recently. ${ }^{32}$ This trial among elderly Turkish patients (with or without vitamin $\mathrm{D}$ deficiency) from a rheumatology outpatient clinic found improvement in pain 4 weeks after administration of a megadose of vitamin D. Regrettably, the authors do not report on the statistical significance of the difference in change between the vitamin D and placebo groups.

\section{Secondary Outcomes}

In our population, we found a statistically significant selfassessed improvement in ability to walk stairs 6 weeks after receipt of vitamin $D$, which likely reflects enhanced strength. Interventional studies showing that vitamin D supplementation has a positive effect on strength have focused mainly on the legs, as have most case reports.

We did not find any improvement in VAS scores for pain. This lack of improvement might reflect greater validity of the verbal Likert scales than the abstract VAS scores in our probably less educated population.

\section{Determinants of Treatment Success}

In our population, patients with a higher VAS score for pain in the legs at baseline had less improvement in pain 6 weeks after vitamin D supplementation. It has long been known that osteomalacia can produce pain in the legs, ${ }^{12}$ but studies have since found vitamin D deficiency to be associated with pain in a variety of other locations. Most of these studies have related vitamin $\mathrm{D}$ deficiency with widespread pain and fibromyalgia, but back pain and also headache have been described as leading symptoms too. ${ }^{29,44,45}$

In our study, these different pain locations did not correlate with improvement on supplementation. Neither did, as expected, pain in the joints. But given the relatively small number of patients, it may have been somewhat problematic to include a large number of important variables in the multivariate model.

\section{Dose and Duration of Supplementation}

A supplementation dose of 100,000 IU vitamin $D_{3}$ is enough to keep $25-\mathrm{OH}$-D levels above $82 \mathrm{nmol} / \mathrm{L}$ for 6 weeks in most patients who start with a level of 60 $\mathrm{nmol} / \mathrm{L} .{ }^{46}$ Six weeks after having received 150,000 IU, our population starting with a mean 25-OH-D level of $20 \mathrm{nmol} / \mathrm{L}$ had reached a mean level of just 63.5 $\mathrm{nmol} / \mathrm{L}$, however; at 12 weeks, the value was even lower, at less than $40 \mathrm{nmol} / \mathrm{L}$. The supplementation dose used thus may have been too low to achieve the full desired impact. The greater improvement at 12 weeks in the vitamin D-vitamin D group compared with the placebo-vitamin D group supports this hypothesis.

\section{Limitations}

Some limitations of our study are due to the type of intervention. First, a single megadose of vitamin D enabled maximal patient compliance, but the duration of treatment might have been too short (as noted above).

Second, the heterogeneity of the enrolled patients may have played a role. We chose inclusion and exclusion criteria to maximize applicability in general practice; specific reasons for the pain were not ascertained. 
Nevertheless, only 3 patients had to be excluded after enrollment because their pain was found to be due to a specific condition, and in the remaining patients, physicians did not mention any specific relevant disease 6 or more months after inclusion. Depression, somatization, and other psychological causes of pain are probably not affected by vitamin $\mathrm{D}_{3}$ but are likely prevalent in patients with chronic musculoskeletal pain ${ }^{47-49}$ as well as in vitamin D deficiency. ${ }^{50-54}$ Because we did not measure psychological conditions, we can only speculate that more selective inclusion criteria would have shown a greater effect of supplementation.

A third limitation is lack of data concerning parathyroid hormone (PTH). This hormone, which increases with low 25-OH-D levels, has direct negative effects on skeletal muscles ${ }^{19}$; therefore, one can argue that vitamin D supplementation is only an indirect approach to improving muscle function. Because correlation between PTH and 25-OH-D levels is rather weak, and in most patients, supplementing vitamin D is the safest way to lower PTH levels, we believe omission of PTH testing is unimportant for clinical practice.

Last, in the multivariate model, our power to assess multiple determinants was limited given the study size.

\section{Possible Mechanisms}

There are several possible mechanisms to explain why vitamin $\mathrm{D}$ supplementation may have a pain-relieving effect: a rapid nongenomic influence of vitamin D on the metabolism of muscle cells, ${ }^{18}$ growth of muscle fibers by a slow genomic effect on muscle cells, and a nonspecific effect on the central or peripheral nervous system. As chronic pain is strongly influenced by mood, an antidepressive effect of vitamin D could also be postulated, ${ }^{50}$ although other investigators have rejected this possibility. ${ }^{55,56}$

In conclusion, we found a small positive effect on pain 6 weeks after high-dose vitamin D supplementation in this RCT in non-Western immigrants in the Netherlands. Although the mechanisms of this benefit are still debatable, future investigation should involve greater numbers of participants and focus on longer follow-up, higher supplementation doses, and mental health.

To read or post commentaries in response to this article, see it online at http://www.annfammed.org/content/10/6/547.

Key words: vitamin D; vitamin deficiency; immigrants; musculoskeletal pain; pain; supplementation; primary care; practice-based research

Submitted October 6, 2011; submitted, revised, February 12, 2012; accepted March 1, 2012.

Acknowledgment: Professor P. Lips (V.U., Amsterdam) commented on an earlier draft of this article. We gratefully accepted some suggestions for improvement.
Trial registration: Title: Vitamin D supplementation and non-specific musculoskeletal disorders. ISRCTN assigned: ISRCTN54027991. Date ISRCTN assigned: June 27, 2007

\section{References}

1. Gloth FM III, Lindsay JM, Zelesnick LB, Greenough WB III. Can vitamin D deficiency produce an unusual pain syndrome? Arch Intern Med. 1991;151(8):1662-1664.

2. Nellen JF, Smulders YM, Jos Frissen PH, Slaats EH, Silberbusch J. Hypovitaminosis $D$ in immigrant women: slow to be diagnosed. BMJ. 1996;312(7030):570-572.

3. Prabhala A, Garg R, Dandona P. Severe myopathy associated with vitamin D deficiency in western New York. Arch Intern Med. 2000; 160(8):1199-1203.

4. Al Faraj S, Al Mutairi K. Vitamin D deficiency and chronic low back pain in Saudi Arabia. Spine (Phila Pa 1976). 2003;28(2):177-179.

5. Plotnikoff GA, Quigley JM. Prevalence of severe hypovitaminosis D in patients with persistent, nonspecific musculoskeletal pain. Mayo Clinic Proc. 2003;78(12):1463-1470.

6. Erkal MZ, Wilde J, Bilgin Y, et al. High prevalence of vitamin D deficiency, secondary hyperparathyroidism and generalized bone pain in Turkish immigrants in Germany: identification of risk factors. Osteoporos Int. 2006;17(8):1133-1140.

7. Mouyis M, Ostor AJK, Crisp AJ, et al. Hypovitaminosis D among rheumatology outpatients in clinical practice. Rheumatology (Oxford). 2008;47(9):1348-1351.

8. Dhesi JK, Jackson SH, Bearne LM, et al. Vitamin D supplementation improves neuromuscular function in older people who fall. Age Ageing. 2004;33(6):589-595.

9. Glerup H, Mikkelsen K, Poulsen L, et al. Hypovitaminosis D myopathy without biochemical signs of osteomalacic bone involvement. Calcif Tissue Int. 2000;66(6):419-424.

10. Bischoff-Ferrari HA, Dietrich T, Orav EJ, et al. Higher 25-hydroxyvitamin $\mathrm{D}$ concentrations are associated with better lower-extremity function in both active and inactive persons aged $\geq 60$ y. Am J Clin Nutr. 2004;80(3):752-758

11. Ward KA, Das G, Berry JL, et al. Vitamin D status and muscle function in post-menarchal adolescent girls. J Clin Endocrinol Metab. 2009;94(2):559-563.

12. Schott GD, Wills MR. Muscle weakness in osteomalacia. Lancet. 1976;1(7960):626-629.

13. de Torrenté de la Jara G, Pécoud A, Favrat B. Musculoskeletal pain in female asylum seekers and hypovitaminosis $D_{3}$. BMJ. 2004; 329(7458):156-157.

14. McBeth J, Pye SR, O'Neill TW, et al; EMAS Group. Musculoskeletal pain is associated with very low levels of vitamin $D$ in men: results from the European Male Ageing Study. Ann Rheum Dis. 2010;69(8): 1448-1452.

15. Helliwell PS, Ibrahim GH, Karim Z, Sokoll K, Johnson H. Unexplained musculoskeletal pain in people of South Asian ethnic group referred to a rheumatology clinic-relationship to biochemical osteomalacia, persistence over time and response to treatment with calcium and vitamin D. Clin Exp Rheumatol. 2006;24(4):424-427.

16. Atherton K, Berry DJ, Parsons T, Macfarlane GJ, Power C, Hypponen C. Vitamin D and chronic widespread pain in a white middleaged British population: evidence from a cross-sectional population survey. Ann Rheum Dis. 2009;68(6):817-822.

17. Simpson RU, Thomas GA, Arnold AJ. Identification of 1,25-dihydroxyvitamin $D_{3}$ receptors and activities in muscle. J Biol Chem. 1985;260 (15):8882-8891.

18. Bischoff HA, Borchers M, Gudat F, et al. In situ detection of 1,25-dihydroxyvitamin $D_{3}$ receptor in human skeletal muscle tissue. Histochem J. 2001;33(1):19-24. 
19. Ceglia L. Vitamin D and skeletal muscle tissue and function. Mol Aspects Med. 2008;29(6):407-414.

20. Bischoff-Ferrari HA, Dawson-Hughes B, Willett WC, et al. Effect of vitamin D on falls: a meta-analysis. JAMA. 2004;291(16):1999-2006.

21. Lips P, Binkley N, Pfeifer M, et al. Once-weekly dose of $8400 \mathrm{IU}$ vitamin $\mathrm{D}_{3}$ compared with placebo: effects on neuromuscular function and tolerability in older adults with vitamin D insufficiency. Am J Clin Nutr. 2010;91(4):985-991.

22. Shaunak S, Colston K, Ang L, Patel SP, Maxwell JD. Vitamin D deficiency in adult British Hindu Asians: a family disorder. Br Med J (Clin Res Ed). 1985;291(6503):1166-1168.

23. Bergman S, Herrström P, Högström K, Petersson IF, Svensson B, Jacobsson LTJ. Chronic musculoskeletal pain, prevalence rates, and sociodemographic associations in a Swedish population study. J Rheumatol. 2001;28(6):1369-1377.

24. Wielders JP, van Dormaël PD, Eskes PF, Duk MJ. Severe vitamin-D deficiency in more than half of the immigrant pregnant women of non-western origin and their newborns [in Dutch]. Ned Tijdschr Geneeskd. 2006;150(9):495-499.

25. Allison TR, Symmons DPM, Brammah T, et al. Musculoskeletal pain is more generalised among people from ethnic minorities than among white people in Greater Manchester. Ann Rheum Dis. 2002;61(2):151-156.

26. Macfarlane GJ, Palmer B, Roy D, Afzal C, Silman AJ, O'Neill T. An excess of widespread pain among South Asians: are low levels of vitamin D implicated? Ann Rheum Dis. 2005;64(8):1217-1219.

27. Grootjans-Geerts I. Hypovitaminosis D: a veiled diagnosis [in Dutch]. Ned Tijdschr Geneeskd. 2001;145(43):2057-2060.

28. van der Heyden JJ, Verrips A, ter Laak HJ, Otten B, Fiselier T. Hypovitaminosis $\mathrm{D}$-related myopathy in immigrant teenagers. Neuropediatrics. 2004;35(5):290-292.

29. Badsha H, Daher M, Ooi Kong K. Myalgias or non-specific muscle pain in Arab or Indo-Pakistani patients may indicate vitamin D deficiency. Clin Rheumatol. 2009;28(8):971-973.

30. Straube S, Derry S, Moore RA, McQuay HJ. Vitamin D for the treatment of chronic painful conditions in adults. Cochrane Database Syst Rev. 2010;(1):CD007771.

31. Wicherts IS, Boeke AJ, van der Meer IM, van Schoor NM, Knol $D L$, Lips P. Sunlight exposure or vitamin D supplementation for vitamin D-deficient non-western immigrants: a randomized clinical trial. Osteoporos Int. 2011;22(3):873-882.

32. Sakalli HAD, Arslan D, Yucel AE. The effect of oral and parenteral vitamin $\mathrm{D}$ supplementation in the elderly: a prospective, doubleblinded, randomized, placebo-controlled study. Rheumatol Int. 2011;32(8):2279-2283.

33. Wolfe F, Smythe HA, Yunus MB, et al. The American College of Rheumatology 1990 Criteria for the Classification of Fibromyalgia. Report of the Multicenter Criteria Committee. Arthritis Rheum. 1990; 33(2):160-172.

34. Warner AE, Arnspiger SA. Diffuse musculoskeletal pain is not associated with low vitamin $D$ levels or improved by treatment with vitamin D. J Clin Rheumatol. 2008;14(1):12-16.

35. Arvold DS, Odean MJ, Dornfeld MP, et al. Correlation of symptoms with vitamin D deficiency and symptom response to cholecalciferol treatment: a randomized controlled trial. Endocr Pract. 2009;15(3):203-212.

36. Burckhardt CS, Jones KD. Adult measures of pain: the McGill Pain Questionnaire (MPQ), Rheumatoid Arthritis Pain Scale (RAPS), Short-Form McGill Pain Questionnaire (SF-MPQ), Verbal Descriptive Scale (VDS), Visual Analog Scale (VAS), and West Haven-Yale Multidisciplinary Pain Inventory (WHYMPI). Arthritis Rheum. 2003; 49(Suppl 5):S96-S104.
37. Clark P, Lavielle $P$, Martínez $H$. Learning from pain scales: patient perspective. J Rheumatol. 2003;30(7):1584-1588.

38. Ferraz MB, Quaresma MR, Aquino LR, Atra E, Tugwell P, Goldsmith $\mathrm{CH}$. Reliability of pain scales in the assessment of literate and illiterate patients with rheumatoid arthritis. J Rheumatol. 1990;17(8):1022-1024.

39. Stockton KA, Mengersen K, Paratz JD, Kandiah D, Bennell KL. Effect of vitamin D supplementation on muscle strength: a systematic review and meta-analysis. Osteoporos Int. 2011;22(3):859-871.

40. Trang HM, Cole DEC, Rubin LA, Pierratos A, Siu S, Vieth R. Evidence that vitamin $D_{3}$ increases serum $25-\mathrm{OH}$-hydroxyvitamin $D$ more efficiently than does vitamin $D_{2}$. Am J Clin Nutr. 1998;68(4):845-848.

41. Armas LAG, Hollis BW, Heaney RP. Vitamin $D_{2}$ is much less effective than vitamin $D_{3}$ in humans. J Clin Endocrinol Metab. 2004;89(11): 5387-5391.

42. Dawson-Hughes B, Heaney RP, Holick MF, Lips P, Meunier PJ, Vieth R. Estimates of optimal vitamin D status. Osteoporos Int. 2005;16(7): 713-716.

43. Heaney RP, Recker RR, Grote J, Horst RL, Armas LA. Vitamin $D_{3}$ is more potent than vitamin $D_{2}$ in humans. J Clin Endocrinol Metab. 2011;96(3):E447-E452.

44. Wandless I, Jarvis S, Evans JG, Aird EG, Stevens J. Vitamin $D_{3}$ in osteoporosis. Br Med J. 1980;280(6227):1320.

45. Schwalfenberg G. Improvement of chronic back pain or failed back surgery with vitamin D repletion: a case series. J Am Board Fam Med. 2009;22(1):69-74.

46. Ilahi M, Armas LAG, Heaney RP. Pharmacokinetics of a single, large dose of cholecalciferol. Am J Clin Nutr. 2008;87(3):688-691.

47. Soares JJ, Jablonska B. Psychosocial experiences among primary care patients with and without musculoskeletal pain. Eur J Pain. 2004;8(1):79-89.

48. Davies KA, Silman AJ, Macfarlane GJ, et al. The association between neighbourhood socio-economic status and the onset of chronic widespread pain: results from the EPIFUND study. Eur J Pain. 2009; 13(6):635-640.

49. Gansky SA, Plesh O. Widespread pain and fibromyalgia in a biracial cohort of young women. J Rheumatol. 2007;34(4):810-817.

50. Jorde R, Sneve M, Figenschau Y, Svartberg J, Waterloo K. Effects of vitamin $D$ supplementation on symptoms of depression in overweight and obese subjects: randomized double blind trial. J Intern Med. 2008;264(6):599-609.

51. Lee JH, O'Keefe JH, Bell D, Hensrud DD, Holick MF. Vitamin D deficiency an important, common, and easily treatable cardiovascular risk factor? J Am Coll Cardiol. 2008;52(24):1949-1956.

52. Hoogendijk WJ, Lips P, Dik MG, Deeg DJ, Beekman AT, Penninx BW. Depression is associated with decreased 25-hydroxyvitamin D and increased parathyroid hormone levels in older adults. Arch Gen Psychiatry. 2008;65(5):508-512.

53. Ganji V, Milone C, Cody MM, McCarty F, Wang YT. Serum vitamin D concentrations are related to depression in young adult US population: the Third National Health and Nutrition Examination Survey. Int Arch Med. 2010;3(3):29.

54. Lee DM, Tajar A, O'Neill TW, et al. Lower vitamin D levels are associated with depression among community-dwelling European men. J Psychopharmacol. 2011;25(10):1320-1328.

55. Schneider B, Weber B, Frensch A, Stein J, Fritz J. Vitamin D in schizophrenia, major depression and alcoholism. J Neural Transm. 2000;107(7):839-842.

56. Zhao G, Ford ES, Li C, Balluz LS. No associations between serum concentrations of 25-hydroxyvitamin $\mathrm{D}$ and parathyroid hormone and depression among US adults. Br J Nutr. 2010;104(11):1696-1702. 